\title{
Fluidity Evaluation of the AC4CH (A356) Aluminum Alloy Semi-Solid Slurry Made by Mechanical Vibration Method*
}

\author{
Yuichiro Murakami ${ }^{1}$, Kenji Miwa $^{2}$, Masayuki Kito $^{3}$, Takashi Honda ${ }^{3}$, \\ Naoyuki Kanetake ${ }^{4}$ and Shuji Tada ${ }^{1}$ \\ ${ }^{1}$ Light metal Casting Process Group, Structural Materials Research Institute, \\ National Institute of Advanced Industrial Science and Technology, Nagoya 463-8560, Japan \\ ${ }^{2}$ Aichi Science and Technology Foundation, Kariya 448-0013, Japan \\ ${ }^{3}$ Die Casting Engineering Section, Die Casting Department, Aisan Industry Co., Ltd., Obu 474-8588, Japan \\ ${ }^{4}$ Materials, Physics and Energy Engineering, Graduate School of Engineering, Nagoya University, Nagoya 464-8603, Japan
}

\begin{abstract}
The semi-solid process is promising as a near-net-shape method for producing high performance products. However, the method is hampered by poor formability because of low fluidity, and difficulty in making the semi-solid slurry. In previous work, we made semi-solid slurries containing small, spherical solid particles by applying mechanical vibration. In this study, we evaluated the fluidity of AC4CH aluminum alloy slurries made by applying mechanical vibration. In addition, we improved the slurry fluidity by applying shear stress to the slurry at the mold gate, and investigated the effect of the shear rate on the fluidity. The slurry was prepared by applying mechanical vibration at a frequency of $50 \mathrm{~Hz}$ and an acceleration amplitude of $166.6 \mathrm{~m} / \mathrm{s}^{2}(17 \mathrm{G})$. The fluidity was evaluated by injecting the slurry through a gate into a metallic mold with a spiral cavity, and measuring the fluidity length. The shear rate at the gate was controlled by changing the thickness of the gate (1.0, 2.2 , and $4.0 \mathrm{~mm}$ ). The fluidity of the slurry made by mechanical vibration was $25 \%$ to $40 \%$ that of liquid aluminum. Applying shear stress at the gate increased the fluidity by approximately $30 \%$. The $\alpha$-phase particles in the specimen became finer and rounder as the shear rate increased. Therfore, semi-solid slurry with high fluidity can be obtained by applying mechanical vibration and increasing the shear rate. Moreover, the slurry prepared by mechanical vibration had similar fluidity to the electromagnetically stirred slurry prepared at high shear rates and casting pressures. Our method could be used to to fabricate complex products by the semi-solid forming process.

[doi:10.2320/matertrans.F-M2015838]
\end{abstract}

(Received September 16, 2015; Accepted November 4, 2015; Published December 18, 2015)

Keywords: aluminum alloy, semi-solid process, semi-solid slurry, fluidity, morphology of solid particles, mechanical vibration

\section{Introduction}

Greenhouse gas emissions and energy consumption are important problems. The majority of primary energy consumption in the transport sector is petroleum-derived. Therefore, increasing the energy efficiency of the transport sector will contribute considerably to energy conservation and greenhouse gas emission reduction. Decreasing vehicle weight by $1 \%$ increases energy efficiency by $1 \%$; therefore, reducing vehicle weight is very important. Aluminum alloys have low densities and high specific strengths, making them suitable for increasing the energy efficiency of transportation equipment.

High-pressure die casting (HPDC) is the most commonly used method for forming products with complex shapes. However, the products formed by HPDC have many casting defects due to air entrainment and so their mechanical strengths vary widely. Moreover, HPDC products cannot be heat treated or welded.

The semi-solid forming process is expected to solve these problems. Casting processes, including HPDC, generally use molten metal, whereas in the semi-solid forming process, the products are formed from a semi-solid, in which a solid and liquid phase coexist. The semi-solid metal has a higher viscosity than the liquid phase, decreasing the gas entrainment during injection into the mold. Moreover, the solidification shrinkage is smaller than for the liquid phase; therefore, the dimensional accuracy is improved and

*This Paper was Originally Published in Japanese in J. Jpn. Foundry Eng. Soc. 86 (2014) 773-780. shrinkage porosity are decreased. The semi-solid process has been examined for aluminum ${ }^{1,2)}$ and magnesium alloys $^{3,4)}$ because of these advantages.

A problem is that the semi-solid forming process has lower formability than HPDC because the fluidity of the semi-solid metal is lower than the liquid phase. Therefore, predicting and increasing fluidity is very important technical issue in semi-solid forming. To increase the fluidity of the semi-solid metal, a slurry with solid particles distributed in liquid metal is required. The fluidity of the semi-solid slurry is increased by fine, round particles. ${ }^{5)}$ We have developed a method of increasing fluidity by applying shear stress during the forming process ${ }^{6-9)}$ that decreases the number of casting defects. ${ }^{10)}$ In addition, semi-solid slurries have been made by applying mechanical vibration (MV). ${ }^{11)}$ In this study, the fluidities of JIS AC4CH aluminum alloy slurries obtained by MV were examined. Moreover, the effect of injection velocity and shear rate on fluidity was examined.

\section{Experimental Procedure}

The fluidity test was performed with a $125 \mathrm{t}$ horizontal HPDC machine. The semi-solid slurry was injected into a spiral cavity ( $4.0 \mathrm{~mm}$ deep, $5.7 \mathrm{~mm}$ wide, $1420 \mathrm{~mm}$ long). A schematic view of the specimen is shown in Fig. 1. A 6.0mm-long gate was placed at the entrance of the cavity. Testing conditions are shown in Table 1 . The shear rate at the gate was altered by changing the injection velocity $(0.1$ or $0.35 \mathrm{~m} / \mathrm{s}$ ) and gate thickness (1.0 or $2.2 \mathrm{~mm}$ ). Additionally, a 4.0-mm-thick gate was also used for conditions without a gate. The plunger diameter was $50 \mathrm{~mm}$, and the casting 


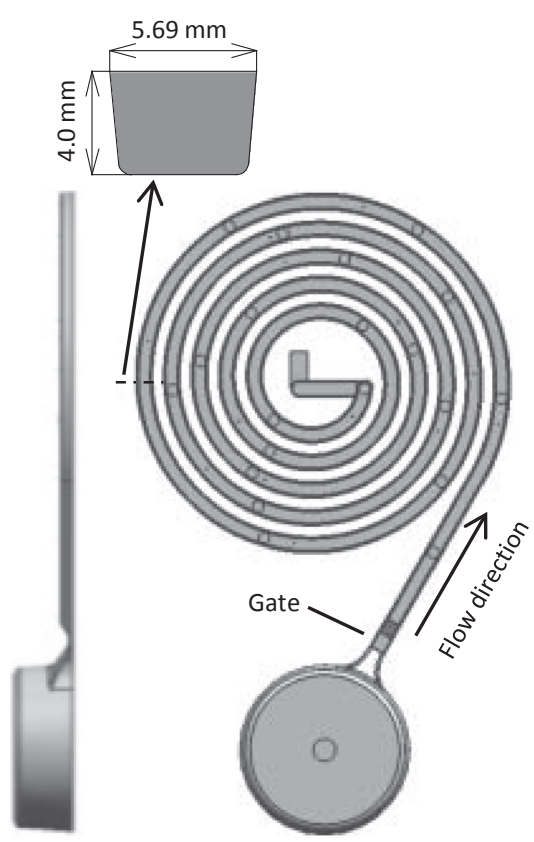

Fig. 1 Schematic illustration of the fluidity test sample.

Table 1 Experimental conditions.

\begin{tabular}{|c|c|c|c|c|c|c|c|}
\hline & \multirow{2}{*}{$\begin{array}{c}\text { Gate } \\
\text { thickness }\end{array}$} & \multicolumn{2}{|c|}{ Injection velocity } & \multicolumn{2}{|c|}{ Casting pressure } & \multirow{2}{*}{$\begin{array}{c}\text { Gate } \\
\text { velocity }\end{array}$} & \multirow{2}{*}{$\begin{array}{c}\text { Shear } \\
\text { rate }\end{array}$} \\
\hline & & $\begin{array}{c}\text { Set } \\
\text { value }\end{array}$ & $\begin{array}{l}\text { Observed } \\
\text { value }\end{array}$ & $\begin{array}{c}\text { Set } \\
\text { value }\end{array}$ & $\begin{array}{c}\text { Observed } \\
\text { value }\end{array}$ & & \\
\hline & $\mathrm{mm}$ & $\mathrm{m} / \mathrm{s}$ & $\mathrm{m} / \mathrm{s}$ & $\mathrm{MPa}$ & $\mathrm{MPa}$ & $\mathrm{m} / \mathrm{s}$ & $10^{4} / \mathrm{s}$ \\
\hline \multirow{12}{*}{ Semi-solid } & 1.0 & 0.1 & 0.10 & 40 & 43.9 & 35.3 & 21.2 \\
\hline & 1.0 & 0.1 & 0.10 & 80 & 75.9 & 35.4 & 21.2 \\
\hline & 1.0 & 0.35 & 0.30 & 40 & 43.9 & 104.9 & 62.9 \\
\hline & 1.0 & 0.35 & 0.31 & 80 & 76.6 & 105.4 & 63.2 \\
\hline & 2.2 & 0.1 & 0.10 & 40 & 43.9 & 16.3 & 4.4 \\
\hline & 2.2 & 0.1 & 0.10 & 80 & 76.4 & 16.1 & 4.4 \\
\hline & 2.2 & 0.35 & 0.30 & 40 & 43.9 & 47.7 & 13.0 \\
\hline & 2.2 & 0.35 & 0.31 & 80 & 76.4 & 47.8 & 13.0 \\
\hline & 4.0 & 0.1 & 0.10 & 40 & 43.9 & 8.9 & 1.3 \\
\hline & 4.0 & 0.1 & 0.10 & 80 & 76.1 & 8.8 & 1.3 \\
\hline & 4.0 & 0.35 & 0.31 & 40 & 43.9 & 26.3 & 3.9 \\
\hline & 4.0 & 0.35 & 0.31 & 80 & 76.4 & 26.4 & 4.0 \\
\hline \multirow{3}{*}{$\begin{array}{l}\text { Liquid } \\
\text { phase }\end{array}$} & 1.0 & 0.1 & 0.10 & 40 & 43.9 & 34.0 & 20.4 \\
\hline & 2.2 & 0.1 & 0.10 & 40 & 43.9 & 16.4 & 4.5 \\
\hline & 4.4 & 0.1 & 0.10 & 40 & 43.9 & 8.7 & 1.3 \\
\hline
\end{tabular}

pressure (final pressure after filling the cavity) was set at 40 or $80 \mathrm{MPa}$. For comparison, the fluidity of the fully liquid phase was measured. The molten alloy $(250 \mathrm{~g})$ at $700^{\circ} \mathrm{C}$ was poured directly into the sleeve and injected into the mold. The mold and sleeve were heated to $250^{\circ} \mathrm{C}$. Fluidity was evaluated as fluidity length, which is the length of the spiral from the spiral tip to the gate.

The AC4CH aluminum alloy slurry was prepared as follows. A stainless steel container with an inner diameter of $38.7 \mathrm{~mm}$, a height of $90.0 \mathrm{~mm}$, and a thickness of $1.2 \mathrm{~mm}$ was vibrated horizontally. A BN release agent was sprayed onto the internal surface to prevent a reaction between the molten metal and the container. The molten AC4CH alloy $(250 \mathrm{~g})$ was poured into the vibrating container. The heat of the

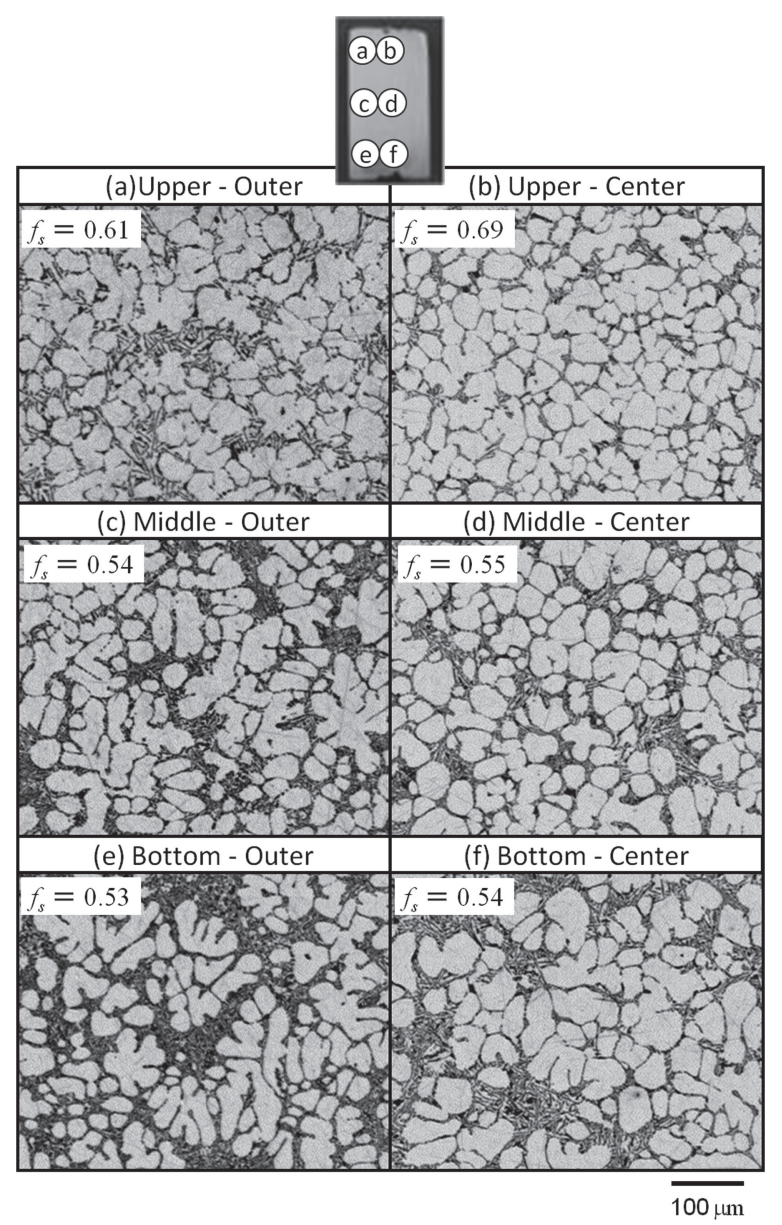

Fig. 2 Microstructures of different regions of the AC4CH alloy MV slurry fabricataed at a frequency of $50 \mathrm{~Hz}$ and an acceleration amplitude of $166.6 \mathrm{~m} / \mathrm{s}^{2}(17 \mathrm{G})$.

molten alloy was drawn out by the container, decreasing the temperature so the alloy was in the semi-solid state. The vibration was applied for $20 \mathrm{~s}$, corresponding to the time required to decrease the temperature of the molten alloy to the semi-solid temperature $\left(590^{\circ} \mathrm{C}\right)$. The vibrations had a frequency of $50 \mathrm{~Hz}$ and an acceleration amplitude of $166.6 \mathrm{~m} / \mathrm{s}^{2}$. Additionally, to examine the microstructure of the semi-solid slurry, a specimen was rapidly cooled in the water for $15 \mathrm{~s}$ after applying MV. The specimen was cut vertically, and the microstructures were observed at the top, middle, and bottom by optical microscopy. The microstructure of the fluidity test specimen was also observed by optical microscopy. The specimens were molded in epoxy resin at room temperature and polished by grinding with $\mathrm{SiC}$ paper and then polished with diamond paste. Then, the specimens were etched in a $0.5 \%$ HF solution.

\section{Results}

\subsection{Microstructure of the slurry before injection}

The microstructures of different areas of the specimen before injection are shown in Fig. 2. Primary $\alpha$-Al particles were dispersed in the alloy matrix (eutectic $\alpha-\mathrm{Al}$ and $\mathrm{Si}$ ). The images suggest that the primary $\alpha$-Al particles were solid and the matrix was liquid before the specimens were cooled rapidly. In the middle (Fig. 2(c), (d)) and bottom-center part 
(Fig. 2(f)) of the specimen, the solid particles were dispersed in the liquid phase, although some dendritic solid particles were visible. However, at the top (Fig. 2(a), (b)) or bottomouter part (Fig. 2(e)) of the specimen, some coarse solid particles were present and the solid fraction was increased. The high solid fraction of 0.55 and coarse solid particles at the top of slurry suggested that the fluidity of the slurry would be low. These low quality slurry was observed at $10 \mathrm{~mm}$ from the top. Therefore, in the following fluidity test, a capture space was created between the sleeve and the mold as a vacancy of $15 \mathrm{~mm}$ in height. The top of the slurry was trapped by this capture space and thus the slurry of low quality was prevented flowing into the cavity.

\subsection{Fluidity test}

The dependence of the fluidity on the gate thickness is shown in Fig. 3. At an injection velocity of $0.1 \mathrm{~m} / \mathrm{s}$ (Fig. 3(a), (b)), the fluidity length was 300-500 mm, which was $25 \%-40 \%$ of the liquid phase. The fluidity length was

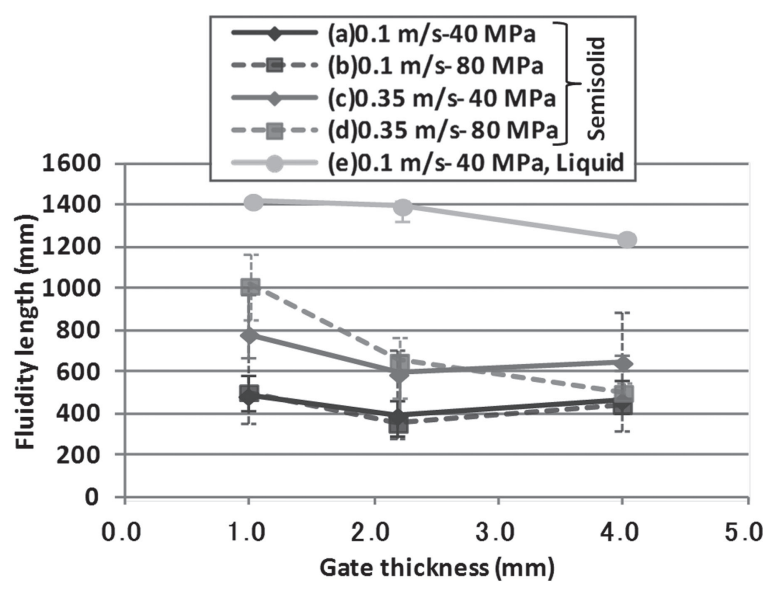

Fig. 3 Relation between gate thickness and fluidity length. increased to $500 \mathrm{~mm}$ at a gate thickness of $1.0 \mathrm{~mm}$. At an injection velocity of $0.35 \mathrm{~m} / \mathrm{s}$ (Fig. 3(c), (d)), the fluidity length was about $600 \mathrm{~mm}$ at a gate thickness of 4.0 or $2.2 \mathrm{~mm}$. However, at a gate thickness of $1.0 \mathrm{~mm}$, the fluidity length was increased to about $800 \mathrm{~mm}$ at a casting pressure of $40 \mathrm{MPa}$ and $1000 \mathrm{~mm}$ at $80 \mathrm{MPa}$. Therefore, the fluidity length was increased by decreasing the gate thickness, and by increasing the casting pressure.

\subsection{Microstructure of the fluidity test specimen}

Microstructures of the specimen in a section vertical to the flow direction in the middle of the fluidity length are shown in Fig. 4. The observations were obtained by using the specimens with a fluidity length nearest the average. Moreover, the microstructures were homogeneous until $60 \%$ of the fluidity length from the gate, which is in agreement with previous results. ${ }^{12)}$ The microstructures were composed of the primary $\alpha$-Al particles dispersed in the matrix (eutectic $\alpha$-Al and $\mathrm{Si}$ ) of the alloys, as in Fig. 2.

For an injection velocity of $0.1 \mathrm{~m} / \mathrm{s}$ (Fig. 4(a), (b)) and a large gate thickness of 2.2 or $4.0 \mathrm{~mm}$, some dendritic primary $\alpha$-Al particles appeared (indicated by the arrow in Fig. 4). However, for a gate thickness of $1.0 \mathrm{~mm}$, the primary $\alpha$-Al particles were fine and rounded. For an injection velocity of $0.35 \mathrm{~m} / \mathrm{s}$ (Fig. 4(c), (d)), coarse primary $\alpha$-Al particles were also observed for a gate thickness of $4.0 \mathrm{~mm}$, although the primary $\alpha$-Al particles became finer and rounder as the gate thickness decreased. This is expected to affect the fluidity of the slurry. In contrast, the casting pressure had little effect on the particle shape and slurry fluidity.

\section{Discussion}

\subsection{Effect of shear rate on fluidity}

First, we discuss the effect of shear rate at the gate on the

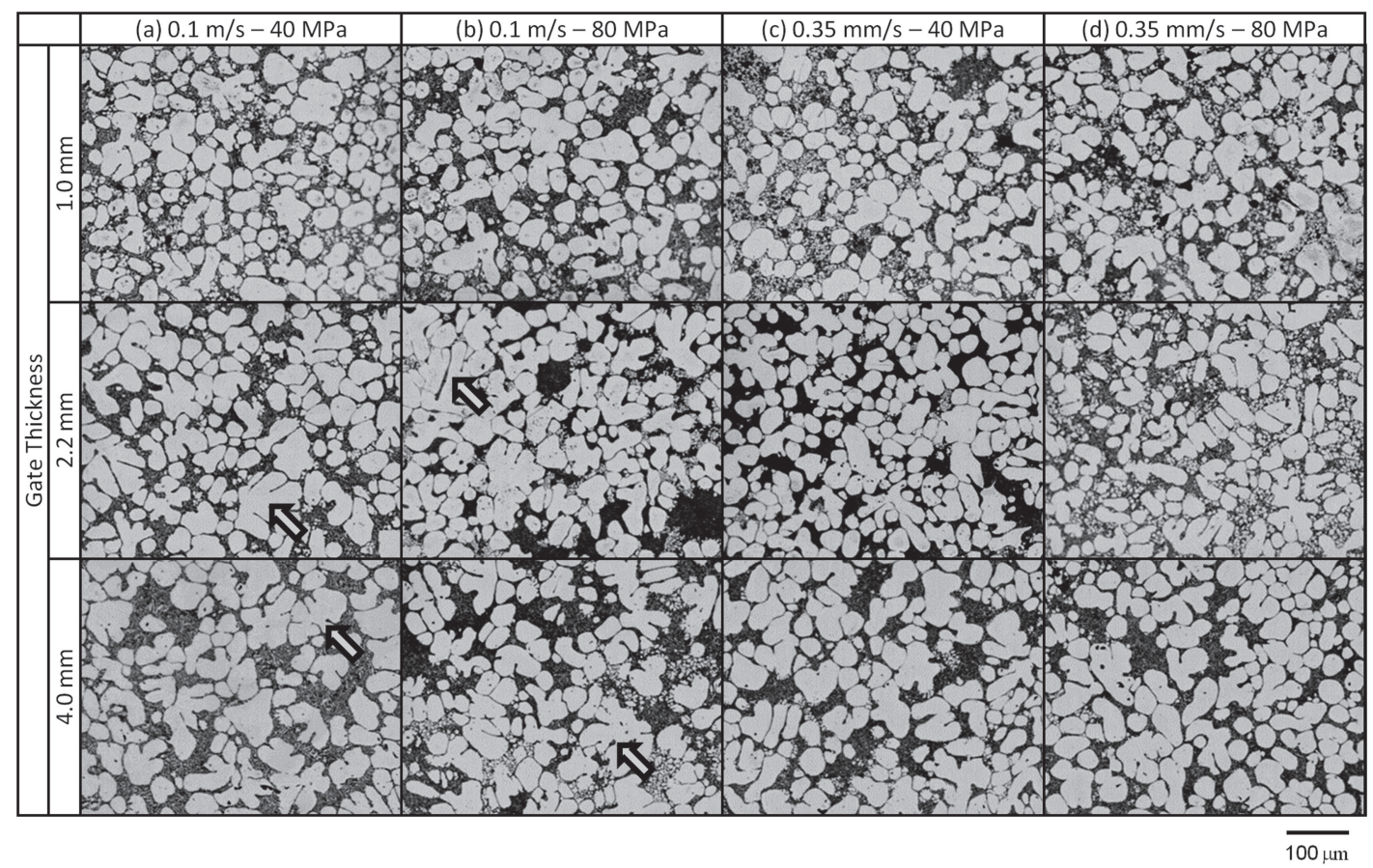

Fig. 4 Microstructures of the central section of the fluidity test specimen in the middle of the total flow length. 


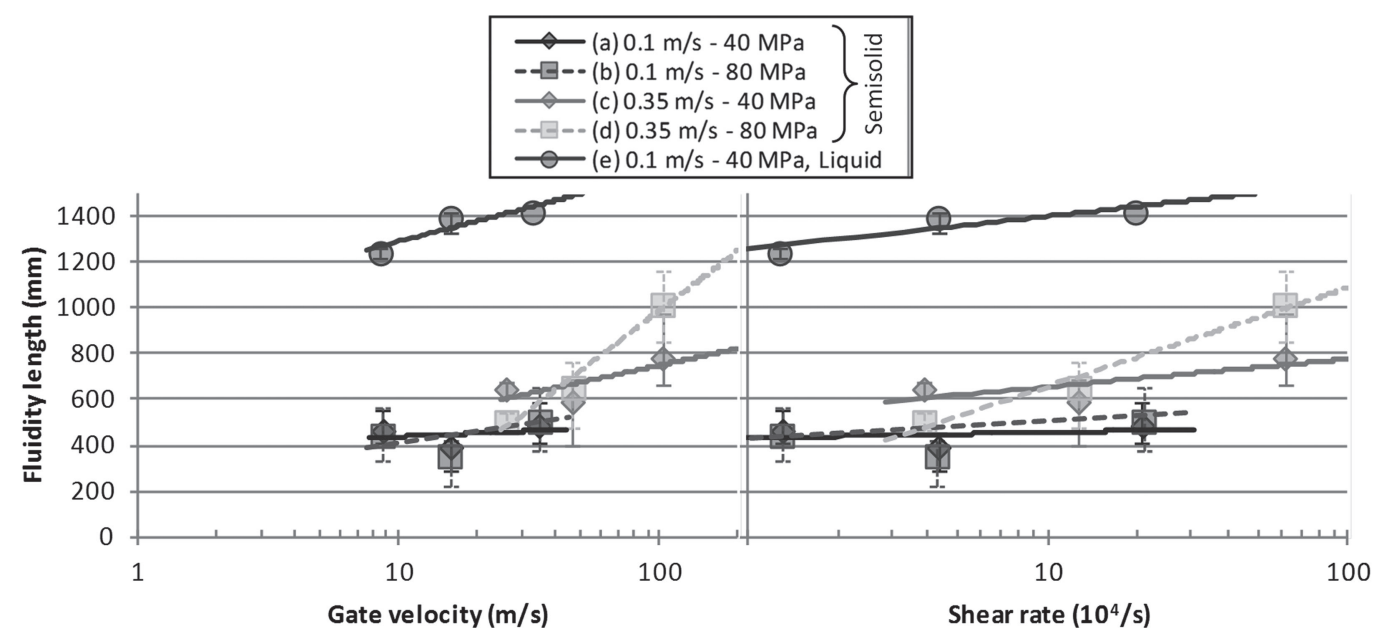

Fig. 5 Effect of gate velocity and shear rate at the gate on fluidity length.

fluidity. The gate velocity at a rectangular cross-section was calculated by

$$
v=Q /(B H)
$$

where $Q$ is the volume flow $\left[\mathrm{m}^{3} / \mathrm{s}\right]$ and $B$ and $H$ are the length of the long side and the short side of the rectangle $[\mathrm{m}]$, respectively. The semi-solid slurry is a thixotropic nonNewtonian fluid. ${ }^{13)}$ The apparent shear rate, $\gamma$, of the nonNewtonian fluid flowing through the rectangular cross section is expressed by the following equation. ${ }^{14)}$

$$
\gamma=6 Q /\left(B H^{2}\right)
$$

The relationship between the gate velocity and the fluidity length, and between the shear rate at the gate and the fluidity length are shown in Fig. 5. The fluidity length increased with increasing gate velocity or shear rate at the gate. At an injection velocity of $0.35 \mathrm{~mm} / \mathrm{s}$, the fluidity length was more affected by the gate velocity and shear rate at the gate than at an injection velocity of $0.1 \mathrm{~m} / \mathrm{s}$.

To evaluate the size and shape of the solid particles quantitatively, the particle roundness, $R$, and the particle diameter, $d[\mu \mathrm{m}]$, were measured by image analysis. The roundness of a particle was calculated by ${ }^{15}$ )

$$
R=L^{2} /(4 \pi A)
$$

where $L[\mu \mathrm{m}]$ and $A\left[\mu \mathrm{m}^{2}\right]$ are the boundary length and area of the solid particle, respectively. When $R=1$, the particle is a perfect sphere and $R$ increases if the shape of the particle deviates from being spherical. Next, the particle diameter (equivalent circle diameter), $d$, was calculated by the following equation.

$$
d=2 \sqrt{A / \pi}
$$

The particle roundness and diameter were calculated for 700 800 particles per sample. The area-weighted mean roundness, $R_{\mathrm{s}}$, and area-weighted mean diameter, $d_{\mathrm{s}}[\mu \mathrm{m}]$, were also calculated from

$$
\begin{aligned}
& R_{\mathrm{s}}=\Sigma R_{\mathrm{i}} A_{\mathrm{i}} / \Sigma A_{\mathrm{i}}, \\
& d_{\mathrm{s}}=\Sigma d_{\mathrm{i}} A_{\mathrm{i}} / \Sigma A_{\mathrm{i}}
\end{aligned}
$$

where $d_{\mathrm{i}}[\mu \mathrm{m}], A_{\mathrm{i}}\left[\mu \mathrm{m}^{2}\right]$, and $R_{\mathrm{i}}$ are the diameter, area, and roundness of a solid particle, respectively. The relations between the mean particle roundness or diameter and gate velocity or shear rate at the gate are shown in Fig. 6. At the same injection velocity, both the mean particle roundness and the mean particle diameter decreased with increasing gate velocity. However, both the mean particle roundness and the mean particle diameter showed the same decrease with increasing shear rate at the gate regardless of the injection velocity. This result is the same as in our previous study, $\left.{ }^{9}\right)$ indicating that the solid particles are deformed by applying shear stress at the gate. Increasing the shear rate makes the particles finer and rounder because the shear stress at the gate is the product of the apparent viscosity and shear rate. Therefore, the primary $\alpha$-Al phases after solidification are also finer and rounder.

The relationship between the mean primary $\alpha$-Al particle roundness, the mean primary $\alpha$-Al particle diameter, and the fluidity length are shown in Fig. 7. The fluidity length was increased with decreasing mean particle roundness or diameter. The viscosity of slurry was decreased by fine, round solid particles. ${ }^{5)}$ Therefore, the flow resistance was decreased by decreasing the viscosity, and the fluidity was increased by the presence of fine, round solid particles. Moreover, at a high shear rate, where the particles are fine and round, the fluidity length was increased by increasing the casting pressure. The tip of the specimen was not restrained in the spiral cavity used in this study. Therefore, the fluidity length was increased by the final pressure after filling the cavity because the slurry was fluid after the flow ceased owing to the decreased viscosity.

The MV slurry had a fluidity length of $25 \%-40 \%$ of the fluidity length of the liquid state. The fluidity length could be increased by about $30 \%$ by applying shear stress higher than $5.0 \times 10^{5} / \mathrm{s}$, because the solid particles became fine and round. Furthermore, the fluidity length could be increased by increasing the casting pressure in the high shear rate range.

\subsection{Fluidity comparison of mechanical vibration slurry with electromagnetically stirred slurry}

In a previous study, ${ }^{9}$ a slurry was made by electromagnetic stirring (EMS; nano-cast method). We compared the fluidity length of slurries made by MV and by EMS. The mean particle diameter and mean particle roundness of the slurries 


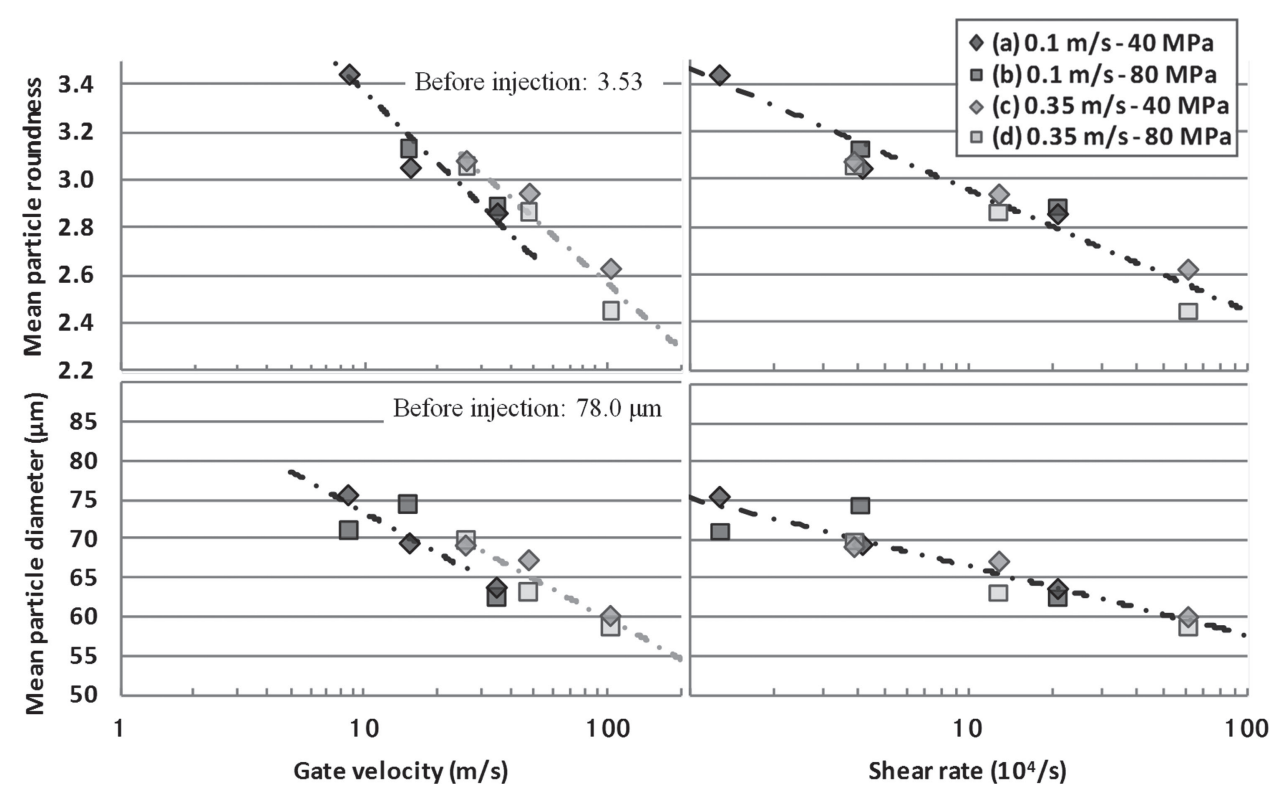

Fig. 6 Effects of shear rate at gate on mean roundness and diameter of primary $\alpha$-Al particles.

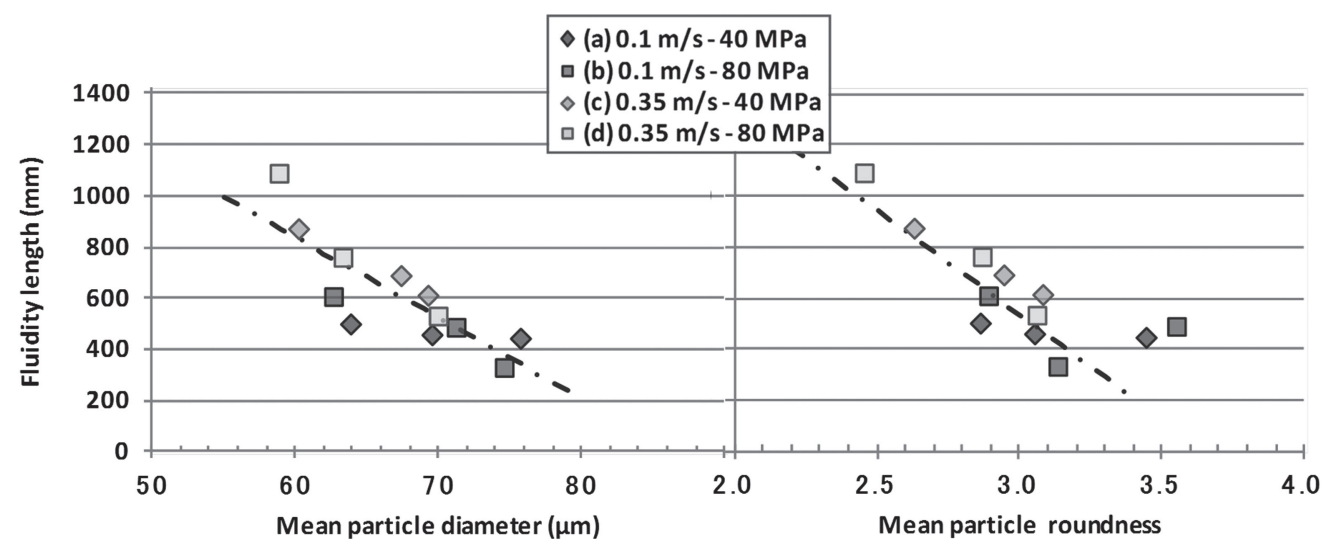

Fig. 7 Effects of mean roundness and diameter of primary $\alpha$-Al particles on fluidity length.

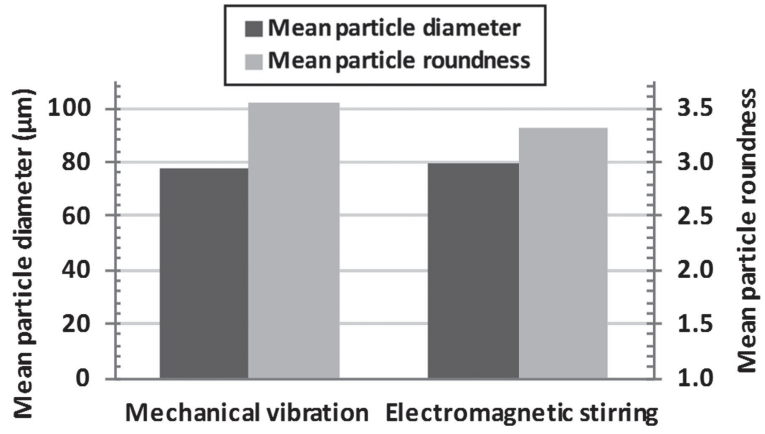

Fig. 8 Mean particle diameter and mean particle roundness of $\alpha$-phase particles in semi-solid slurry prepared by MV or EMS.

before injection is shown in Fig. 8. The mean particle diameter of the MV slurry was similar to the EMS slurry, whereas the mean particle roundness was greater than for the EMS slurry. The solid fraction of both slurries was about 0.55 .

In both this and previous studies, experiments were performed with the same mold, but with different HPDC machines. The results for casting with the liquid alloy under the same casting conditions were different because of the difference between the machines. Hence, the results of the studies could not be compared directly. The relative fluidity length was calculated based on the liquid phase results to compare the results. The fluidity length, $l_{\mathrm{L}}$, for the liquid phase with an injection velocity of $0.1 \mathrm{~m} / \mathrm{s}$ in and a gate thickness of $4.0 \mathrm{~mm}$ in was used as a reference value. The relative fluidity length, $l_{\mathrm{Ri}}$, was calculated from $l_{\mathrm{i}}$ under each set of conditions from

$$
l_{\mathrm{Ri}}=l_{\mathrm{i}} / l_{\mathrm{L}} \text {. }
$$

Figure 9 shows the relation between $l_{\mathrm{Ri}}$ and gate velocity or shear rate at an injection velocity of $0.35 \mathrm{~m} / \mathrm{s}$. The relative fluidity length of the MV slurry was lower than the EMS method under low gate velocity or shear rate conditions. In particular, at a casting pressure of $80 \mathrm{MPa}$, the MV slurry had similar fluidity to the EMS slurry.

The relation between the relative fluidity length and the mean diameter or mean roundness of primary $\alpha$-Al phase particles in the fluidity test specimen are shown in Fig. 10. The mean primary $\alpha$-Al particle diameter in the MV slurry was slightly lower than that in the EMS slurry, and thus the relative fluidity length was also lower for the same mean 


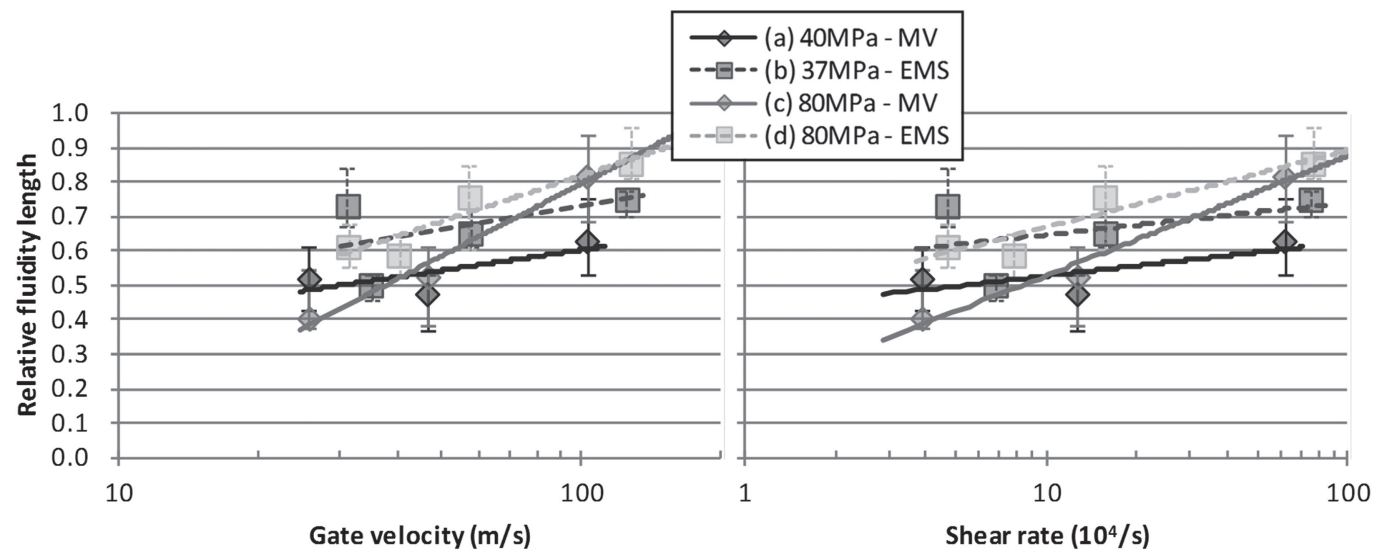

Fig. 9 Comparison of the effects of gate velocity and shear rate on relative fluidity length in MV and EMS slurry at an injection velocity of $0.35 \mathrm{~m} / \mathrm{s}$.

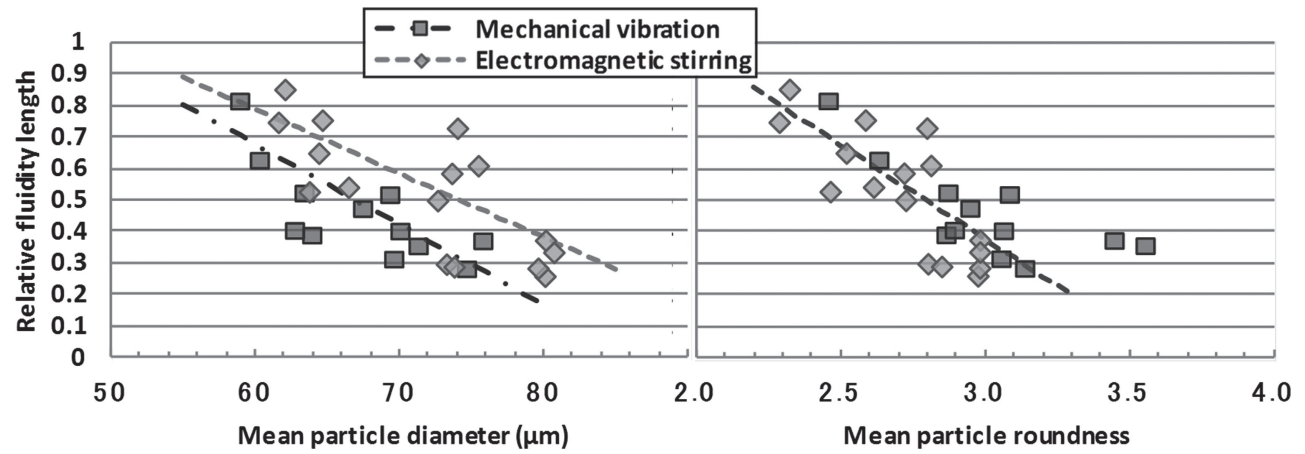

Fig. 10 Comparison of the effects of mean particle diameter and mean particle roundness of $\alpha$-phase particles on relative fluidity length in MV slurry and EMS slurry.

primary $\alpha$-Al particle diameter. However, the mean primary $\alpha$-Al particle roundness of the MV slurry was greater than that in the EMS slurry if similar diameter. Consequently, in the fluidity test specimen, the primary $\alpha$-Al phase particles of the EMS slurry were slightly coarse but rounder than those of the MV slurry. The EMS slurry had a higher fluidity than that in the MV slurry. The relative fluidity length was strongly related to the mean particle roundness, independent of the different slurry preparation methods. This suggests that the fluidity of slurry was affected by the shape of the solid particles rather than the size.

The MV slurry developed in this study has a high fluidity, which is similar to EMS slurry, at high shear stress and high casting pressure.

\section{Conclusion}

The fluidity of JIS AC4CH aluminum alloy slurry made by MV method was examined by using a high-pressure die casting machine. The effect of the shear rate on the fluidity was investigated by varying the gate thickness. The effect of the shear rate at the gate on the microstructures of the specimens was observed. The following conclusions were obtained from the results.

(1) At low shear rates, the fluidity of the MV slurry was $25 \%$ to $40 \%$ that of the liquid alloy. The fluidity of the slurry was increased by about $30 \%$ by increasing the shear rate, demonstrating that the formability can be improved.
(2) The fluidity of the MV slurry at a high shear rate and casting pressure was similar to the EMS slurry.

(3) The fluidity of the semi-solid slurry was affected by the diameter and shape of the solid particles, although the effect of the shape was greater than the diameter.

\section{REFERENCES}

1) C. G. Kang, Y. J. Jung and S. W. Youn: J. Mater. Process. Technol. 135 (2003) 158.

2) Z. Fan, X. Fang and S. Ji: Mater. Sci. Eng. 412 (2005) 298.

3) Z. Fan, G. Liu and Y. Wang: J. Mater. Sci. 41 (2006) 3631.

4) F. Czerwinski: Scr. Mater. 48 (2003) 327.

5) M. Hirai, K. Takebayashi and Y. Yoshikawa: ISIJ int. 33 (1993) 405412.

6) K. Miwa, R. S. Rachmat, T. Tamura and K. Sakaguchi: J. JFS 78 (2006) 193 (in Japanise).

7) Y. Murakami, N. Omura, M. G. Li, T. Tamura and K. Miwa: Mater. Trans. 53 (2012) 1094-1099.

8) Y. Murakami, K. Miwa, N. Omura and S. Tada: Mater. Trans. 53 (2012) 1775-1781.

9) Y. Murakami, K. Miwa, M. Kito, T. Honda, N. Kanetake and S. Tada: Mater. Trans. 54 (2013) 1788-1794.

10) Y. Murakami, K. Miwa, M. Kito, T. Honda, N. Kanetake and S. Tada: Shape Casting: 5th International Symposium 2014, (2014) p. 11.

11) Y. Murakami, K. Miwa, M. Kito, T. Honda, N. Kanetake and S. Tada: J. JFS 86 (2014) 728 (in Japanese).

12) Y. Murakami, K. Miwa, M. Kito, T. Honda, N. Kanetake and S. Tada: Mater. Trans. 56 (2015) 206-211.

13) P. A. Joly and R. Mehrabian: J. Mater. Sci. 11 (1976) 1393.

14) Japanese Industrial Standards Committee: JIS K7199 (1999) 12.

15) V. Mikli, H. Käerdi, P. Kulu and M. Besterci: Proc. Estonian Acad. Sci. Eng. 7 (2001) 22-34. 